\title{
U.S. Immigration Reform and the Migration Dynamics of Mexican Males
}

\author{
Khulan Altangerel $^{1}$ (D) · Jan C. van Ours O $^{2,3,4,5,6}$
}

\begin{abstract}
The 1986 US Immigration Reform and Control Act (IRCA) was directed at tackling the problem of growing unauthorized migration through legalization of unauthorized immigrants, increasing border security and sanctioning employers who hired unauthorized immigrants. Our paper investigates how the IRCA affected the migration dynamics of male Mexican immigrants focusing on their age of onset of migration and the duration of their first trip. We find that the IRCA reduced unauthorized migration to the US while it does not seem to have had a significant effect on the return rate from the US to Mexico of undocumented male immigrants.
\end{abstract}

Keywords Immigration policy · Migrant behavior · Undocumented immigrants

JEL Classification J61 $\cdot$ J68 $\cdot$ J15

Khulan Altangerel

k.altangerel@uvt.nl

Jan C. van Ours

vanours@ese.eur.nl

1 Department of Economics and CentER, Tilburg University, Tilburg, The Netherlands

2 Erasmus School of Economics, Tinbergen Institute, Erasmus University Rotterdam, Rotterdam, The Netherlands

3 Department of Economics, University of Melbourne, Parkville, Australia

4 CEPR, London, UK

5 CREAM, London, UK

6 IZA, Bonn, Germany 


\section{Introduction}

Immigration policies restrict the entrance of persons from other countries. There is a range of these policies from quotas that establish a maximum number of work and residence permits to be issued to foreigners to admission criteria that limit access (Boeri and van Ours 2013). Admission criteria can be based on a point system in which individual-specific characteristics such as education, experience and language abilities are important. Admission criteria can also be based on family relationships or labor market conditions such as shortage of specific skills. During a large part of the twentieth century U.S. immigration was restricted through quota while over the last decades it was largely determined by family considerations, i.e. entry visas were assigned to those who had family members already in the U.S. (Daniels 2002). The annual number of immigrants to the U.S. increased from a quarter of million in the 1950s to nearly half a million in the 1970s and close to a million in the 1990s. In the same time period, there was also big change in the source composition with a sharp rise in immigration from Asia and Mexico. In addition to the sharp rise of legal migration to the U.S. there was a big increase in unauthorized immigration, especially from Mexico (Clark et al. 2007).

The Immigration Reform and Control Act (IRCA) of 1986 was the first legislative reform aimed at tackling the growth of unauthorized immigrants. It intended to control and deter illegal immigration to the US through legalization of unauthorized immigrants, increased border security, and sanctions on employers which hired unauthorized immigrants. The law gave a legal status to about 2.7 million unauthorized immigrants in the years following its enactment (Baker 2010). Despite this effort, the number of illegal migrants residing in the US continued to grow and stabilized at about 11 million since 2005 (Baker and Rytina 2013; Passel and Cohn 2016).

We evaluate the effects that the IRCA had on the migration dynamics of Mexican males. Changes in immigration law can affect the migrant stock in a country through several channels. A policy change may have an effect through both migrant inflow and outflow which in turn depend on the propensity to migrate to the country, the duration of stay, and the average number of trips each immigrant makes. Our study aims to investigate the overall effect of the IRCA on a Mexican-born individual. We distinguish between the effect on the propensity of taking a first unauthorized trip to the US and the duration of the first stay in the US. In doing so, we attempt to separate the effects of the IRCA on the duration of stay of those migrants who are unauthorized throughout their stay from those who eventually receive legal status, as legalization limits the newly legal migrant's return behavior. ${ }^{1}$ We compare the results with those of legal immigrants. To measure the overall effect of the reform we use a timing-ofevents approach. In particular, we estimate a multivariate migration rate model which aims to detect a change in the age of initial migration and that of a return following the change in law. In our empirical analysis, we use survey data of Mexican households provided by the Mexican migration project (MMP).

\footnotetext{
${ }^{1}$ Immigrants who stay longer than 6 months outside the US risk losing their legal permanent residence permits.
} 
Since the IRCA is a comprehensive policy change that may have affected all immigrants to the US there is no natural control group. Thus, previous studies on the effect of the IRCA use different identification strategies. Orrenius and Zavodny (2003) and White et al. (1990) use time dummies to measure the effect of the IRCA on apprehension levels to ascertain whether the policy reduced undocumented migration. Donato et al. (1992) also used annual time dummies to analyze the trend of first and repeat migration and apprehension levels after the IRCA. White et al. (1990) find that the IRCA reduced apprehension rates in the first 2 years, further analysis reveals that apprehensions fell in the few months after the law but reverted to the pre-IRCA levels after that (Orrenius and Zavodny 2003). Donato et al. (1992) also agree that the IRCA did not affect the rate of migration to the US and find that it did not change repeat migration patterns either. ${ }^{2}$

Several studies on migrants in the US differentiate between individuals whose trip initiated before and after the IRCA. The conclusion from these studies is mixed. Reyes (2001) and Li (2016) find that the duration of Mexican migrants trip increased for those who moved after the IRCA, while Quinn (2014) finds no change. However, this analysis does not take into account the effect of the IRCA on the many migrants whose trip started before the policy but lasted long enough to be affected by it.

Similar to the work of Donato et al. (1992), we attempt to identify the effect of the IRCA by observing the change over time in a Mexican individual's conditional probability of migration and return. However, we use an alternative identification strategy by examining the year-by-year change in the conditional probability of migrating and the conditional probability of return migration. As in comparable migration studies, we focus on Mexican males distinguishing various groups of immigrants. ${ }^{3}$ The legal immigrant population of the US consists of two groups of migrants. Legal residents are non-citizens allowed to live and work in the country permanently by a permit termed legal permanent resident (LPR). Naturalized citizens are foreign-born individuals who became citizens of the US. The non-immigrant population or temporary migrants include students, holders of various temporary work permits and their family but does not include short-term visitors for pleasure and business. Lastly, unauthorized migrants, also known as illegal immigrants and illegal residents, are foreign-born individuals who reside in the US but are neither legal immigrants, temporary migrants, nor short-term visitors. In our analysis we focus on unauthorized immigrants from Mexico who entered the US without authorizing documents and legal immigrants who hold

\footnotetext{
2 Researchers have studied the effect of the IRCA on other aspects of migration as well. To evaluate the effect of the legalization component, comparison of legalized individual's behavior before and after the IRCA is common as well as comparison of legalized individuals with comparable native population (Amuedo-Dorantes et al. 2007; Amuedo-Dorantes and Bansak 2011; Kossoudji and Cobb-Clark 2000). Another strategy to measure the overall effect of the IRCA is to use the change in the legalized population as proxy for the IRCA (Reyes 2004; Massey and Espinosa 1997; Baker 2015). Arguing that legalization was the most salient part of the law, Baker (2015) uses the ratio of legalized migrant population in a county to identify the effect of the IRCA on the level of crime.

3 In Altangerel and van Ours (2017) we analyzed the effects of the IRCA on all Mexican immigrants to the US finding that Mexican men and women tend to have different immigration behavior.
} 
LPR permits. ${ }^{4}$ We find that the IRCA was effective in reducing the first-time uptake of an unauthorized trip to the US by young males. The IRCA has not affected their initial duration of stay. In addition, the IRCA did not affect the legal migration rate or the return from a legal trip by Mexican immigrants.

Our contribution to the literature on immigration policy is threefold. First, we provide a concise account of unauthorized migrants' behavior after the introduction of the IRCA. We investigate whether there was indeed a one-time effect and assess the effectiveness of the IRCA in reaching its objectives. Second, we study the effect of the immigration policy on the age of onset of migration and the duration of the first migration spell using hazard rate analysis. Hazard rate analysis has the advantage of allowing for time-varying variables to affect an individual's behavior over time. It also takes into account that the behavior of an individual may change as the individual gets older or as the trip progresses. Third, we use a rich dataset that covers migrants from 154 communities in 24 out of 32 states in Mexico. The large dataset allows us to measure both migration and return behavior over time in each individual and take into account important factors that affect behavior.

Our paper is structured as follows. In the next section, we give a brief overview of the IRCA and the Mexican immigration to the US. Section 3 describes our data from the Mexican migration project. Section 4 sets out the empirical migration rate model based on the age of onset of migration and presents relevant parameter estimates. Section 5 discusses the set-up of the return migration model based on the duration of the first trip and presents related parameter estimates. Section 6 concludes.

\section{Immigration Reform and Control Act}

Under the legalization program of the IRCA 3.0 million illegal immigrants applied for legal residence and 2.7 million of them eventually received a permanent resident status (Baker 2010). Of these, 1.1 million received LPR permits as a special agricultural worker. The legalized migrants represented the majority of the 3-5 million illegal immigrants present in the country at the time (Rytina 2002). Illegal immigrants who demonstrated eligibility to legal residence under the law were not subject to deportation and were allowed to work upon enactment of the law. The application window lasted for 12 months starting in May 1987. Eligible migrants received a legal temporary residence permit and 1.5 years later were able to apply for LPR permits. Thus $95 \%$ of the actual receipt of residence permits happened during the period of 1989-1991 [Fig. 1; Baker (2010)]. Those legalized under the IRCA were not subject to the annual quota for granting of LPR permits that generally apply to legal migration. About $70 \%$ of the applicants under the IRCA legalization program were immigrants from Mexico.

As a second major component of the IRCA, border enforcement staff were increased by $50 \%$. The budget allocated for the Border Patrol increased $82 \%$ between 1986 and 1991. However, due to the increase in time allocated to other non-border activities,

\footnotetext{
4 Thus, the legal immigrants in our analysis do not include citizenship holders, as only $0.5 \%$ of our migrant sample held citizenship at the time of their first entry, in contrast with the $8 \%$ who held LPR permits and $83 \%$ who entered unauthorized.
} 


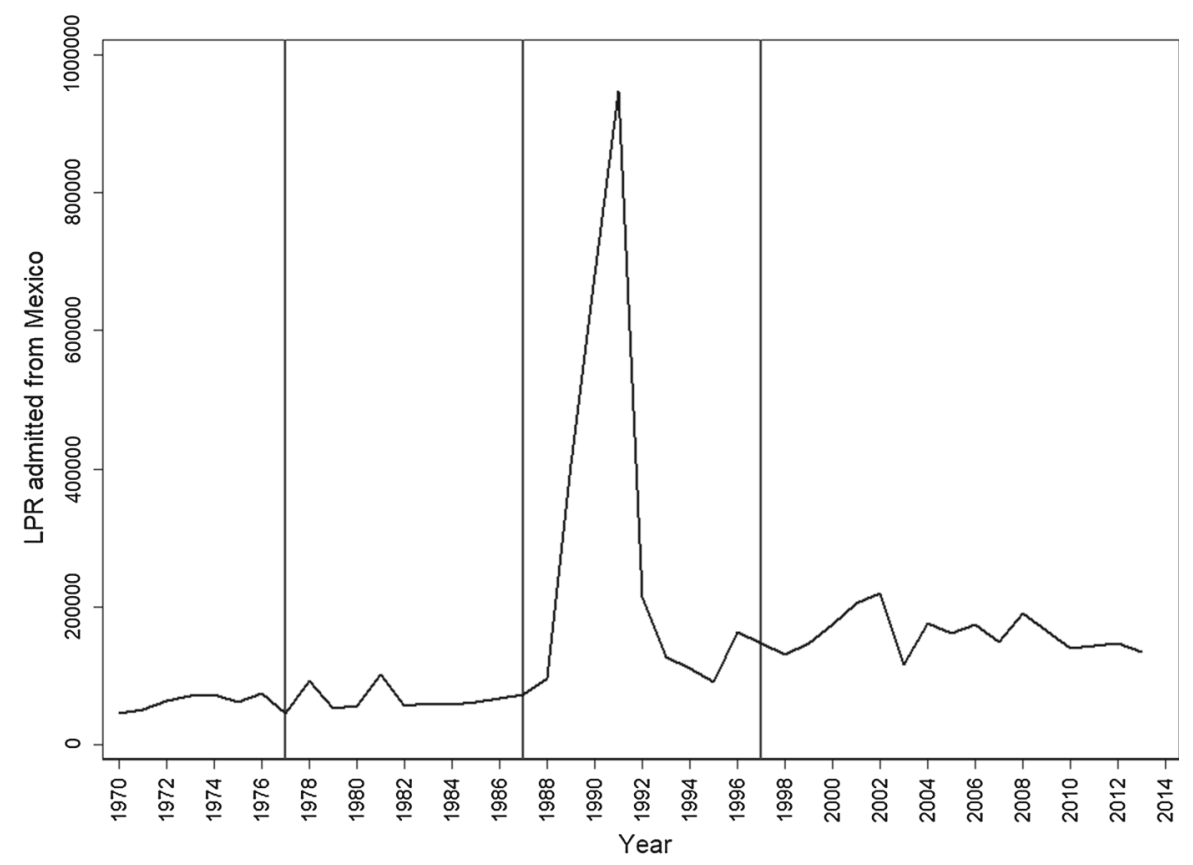

Fig. 1 Legal residence permit holders admitted annually from Mexico. Source MMP

per-officer time spent on patrolling the border declined significantly resulting in a modest change in the levels of total time spent on border patrol activities [see Fig. 2; U.S. General Accounting Office (1992)]. In 1994, the number of border enforcement staff as well as the time spent on border patrol activities took a sharp upturn.

Lastly, the IRCA introduced, for the first time in the US, employer sanctions for hiring unauthorized immigrants, which potentially affected 7 million employers in the US (General Accounting Office, 1987). With the introduction of the IRCA, employers were required to verify and document new recruits' identities and work permits. After a 2 year public education period, employer sanctions came into full effect in 1988. The Government Accountability Office reported in 1990 that the initial implementation of the IRCA was satisfactory (U.S. General Accounting Office 1990). However, due to fear of discrimination against foreign workers, the employers' burden of verification was relatively small and enforcement of the policy fell over the years (Fig. 3; US Congress. Senate. (1996); Cooper and O’Neil (2005).

\section{Mexican Migration Project}

Our data are from the Mexican migration project (MMP154), an annual survey of Mexican households conducted by a team of researchers based at the University of 


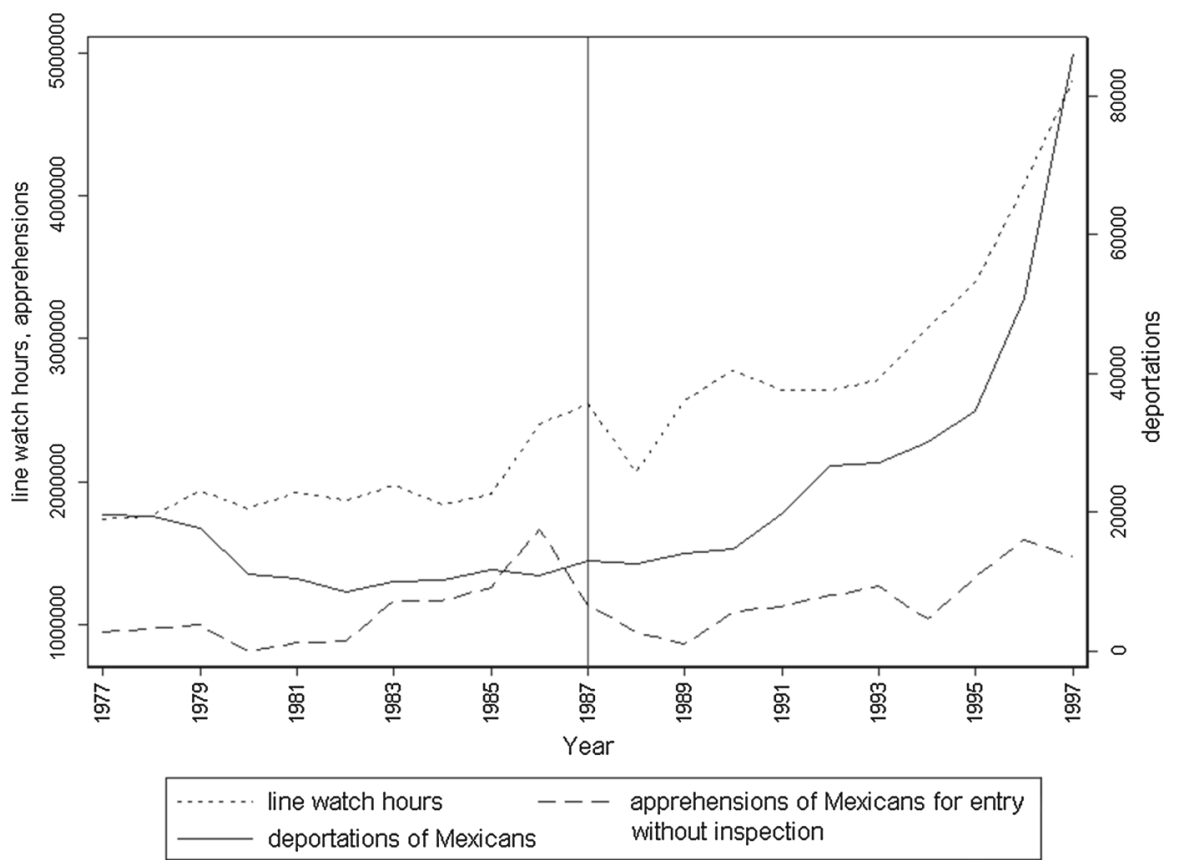

Fig. 2 Border enforcement. Source MMP

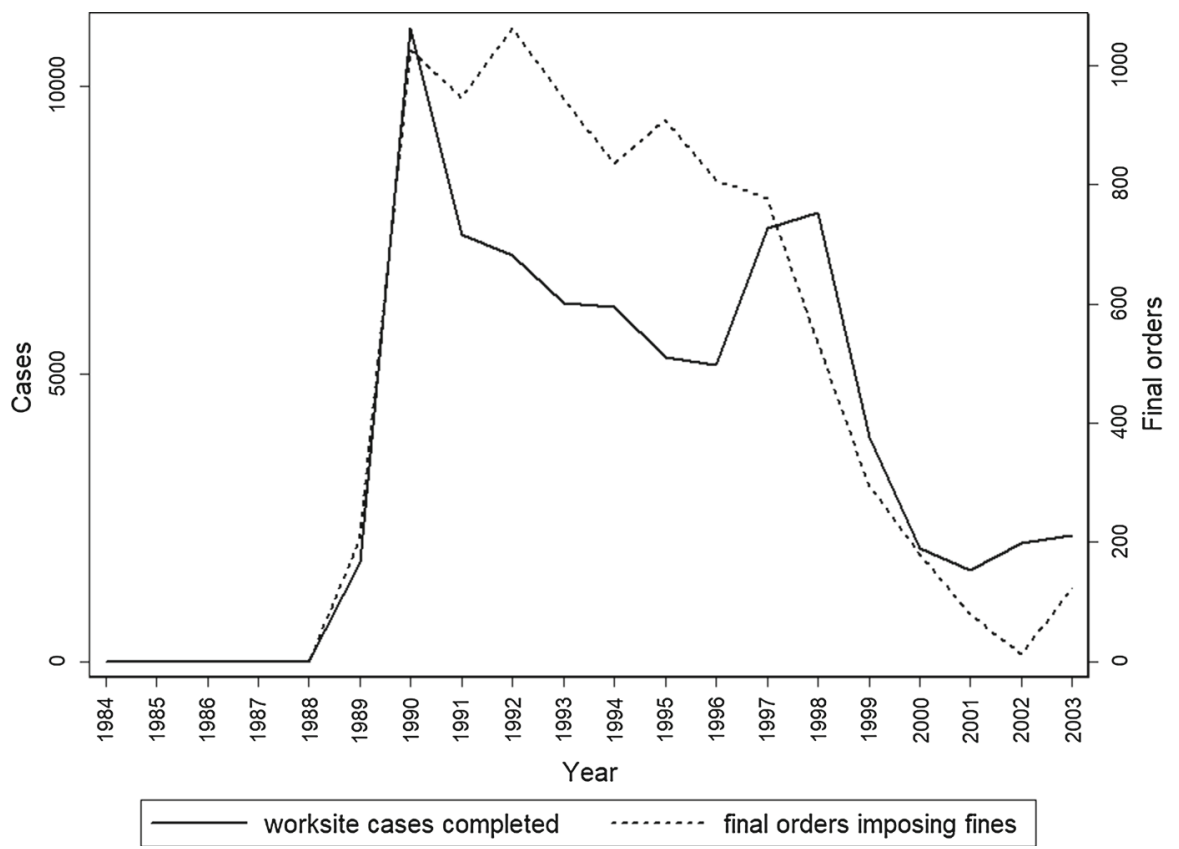

Fig. 3 Employer sanctions. Source Author's calculations based on 1997-2003 yearbooks of immigration statistics (USDHS) and Brownell (2017) 
Guadalajara and Princeton University. ${ }^{5}$ The collection of social and economic data on the Mexico-US migration started in 1982 and is freely accessible for research.

Every year the MMP research team chooses 3-5 communities in Mexico nonrandomly, with the objective to include communities with positive out-migration to the US and to obtain a representative sample of small villages, towns, mid-size cities as well as metropolitan areas (Durand and Massey 2004b). The team interviews a random sample of about 200 households in each community. They collect information about each member of the household, both those in Mexico and the US, in addition to socio-economic characteristics of the household. If a household member ever took a migratory trip to the US, the year of the first trip, the number of trips, documentation and duration information on the first and last trips to the US are recorded. Although the researchers interview households mainly in Mexico they also interview a small number ( $3.1 \%$ of individuals in the MMP154 sample) that originate in these communities but are located in the US. The latter represent the sample of permanent settlers in the US.

Since 1982, the MMP survey covered 154 different communities in 24 states out of 32 in Mexico. A great advantage of MMP-data over other sources of migrant data is that it distinguishes between various types of entry - undocumented, as a naturalized citizen, or a permanent resident, with a tourist visa, or a work visa. The survey also notes whether and when an immigrant received legal immigrant status. Despite being non-representative it is argued that the MMP data correctly captures the migration behavior of an average Mexican immigrant. ${ }^{6}$

The MMP dataset defines a trip to the US if it is to a residence that involves employment, search for work, or an otherwise 'reasonably stable' residence (Mexican Migration Project and Latin American Migration Project 2012). A short trip to the US for tourism or family visit purposes is not considered a trip nor is a trip that was cut short at the outset by a border apprehension. Likewise, a short trip to Mexico during a residence in the US is not considered to be a return trip. Due to unidentifiability of the communities in the MMP, we use municipality and community data supplied by the MMP measured by censuses of 1960, 1970, 1980, 1990, 2000 and 2010. Thus, municipality characteristics in our data take their nearest available values. The documentation that a migrant had at the time of their first main job is defined as the entry documentation and defines whether the first trip in our data is considered unauthorized or legal. "Appendix A" provides details on the data we used.

\footnotetext{
5 The MMP database and codebook are available from mmp.opr.princeton.edu.

${ }^{6}$ As the survey tends to over-sample communities with significant levels of migration to the US, the data are representative of the communities surveyed but not of the Mexican population or all Mexican immigrants to the US (Durand and Massey 2004a). Furthermore, those who migrated to the US as a whole family are less likely to be covered since the household is not in Mexico to be surveyed. As long term migrants are more likely to have traveled as a whole family, this may bias the MMP sample toward migrants with shorter durations. Durand and Massey (2004a) compared the MMP with the National Survey of Population Dynamics (ENADID) conducted by the Mexican National Institute of Statistics and Geography (INEGI) which is representative of the Mexican population with migration experience to the US. They concluded that, except for community location and size, the main characteristics and US trip duration of MMP migrants and ENADID migrants to the US are consistent. Hanson (2006) compared the MMP with the Mexico's Census of Population and Housing and the Mexican-born migrants in the US Census of Population and Housing concluding that the characteristics of the non-seasonal (permanent) migrants in both samples are similar.
} 


\section{First Migration to the US}

\subsection{Descriptives}

We assume that individuals do not migrate before age 15 and we model the duration until first migration as the age of onset minus $14 .{ }^{7}$ We focus on unauthorized migration and migration with an LPR document and specify the age of onset of migration in a competing risk model to allow for dependence in an individual's hazard rates of unauthorized and legal migration. We observe all male individuals who turned 14 between 1976 and 1985 (within a 10-year period before IRCA) and follow them until the age of 35. The dependent variable in the age of onset analysis is the number of years from age 14 until an individual takes his or her first legal or unauthorized migration to the US or is right-censored by age 36 , the survey, death, or migration to the US with another type of documentation, for example a tourist visa.

Figure 4a shows the conditional migration rates by age for an individual's first trip to the US. These rates are specified as the probability to migrate at a certain age conditional on not having migrated up to that age. We distinguish between undocumented migration ("unauthorized migration"), migration with an LPR permit ("legal migration") and other types of documents. Clearly, the undocumented migration rate is by far the largest. It increases from about $1.3 \%$ at age 15 to about $3.5 \%$ at age $18-20$ and slowly declines after that. The legal migration rates and other type of migration rates are all below $0.5 \%$ per year. Figure $4 \mathrm{~b}$ shows the related survivor rates. By their midthirties about 34\% of the Mexicans in our sample have taken at least one unauthorized trip to the US. The other ways of migration to the US are relatively very small.

\subsection{Statistical Model}

We model the age of onset of migration using a mixed proportional hazard (MPH) specification. The MPH specification assumes a proportional effect of observed covariates and unobserved individual-specific components. Likewise, the effect of the IRCA is assumed to be multiplicative. An individual migration rate to destination $u$ (unauthorized) or $l$ (legal) at duration (age) $t$ conditional on observed characteristics $x_{t}$, the time-varying policy regime $D_{t}$ and time-invariant unobserved characteristics $v$ is specified as follows (ignoring a subscript for individual):

$$
\theta^{j}\left(t \mid x_{t}, D_{t}, v_{j}\right)=\lambda_{j}(t) \exp \left(x_{t} \beta_{j}+\delta_{\mathrm{IRCA}, j} D_{t}+v_{j}\right) \quad \text { for } \quad j=u, l
$$

The vector of background parameters to be estimated is represented by $\beta_{j}$. The vector of covariates $x_{t}$ includes time-invariant and time-varying variables. Time-invariant variables include education at the time of the survey ${ }^{8}$, migrant cohort represented by birth year minus 1950, and the community share of household heads who were in

\footnotetext{
${ }^{7}$ Age 15 is the age around which individuals may decide to embark on a migration trip independently. In the original sample of all migrants more than half of the migrants had traveled to the US before the age of 21 , but only $9 \%$ had migrated the age of 14 .

8 We take education as a proxy for unobserved ability of an individual migrant.
} 


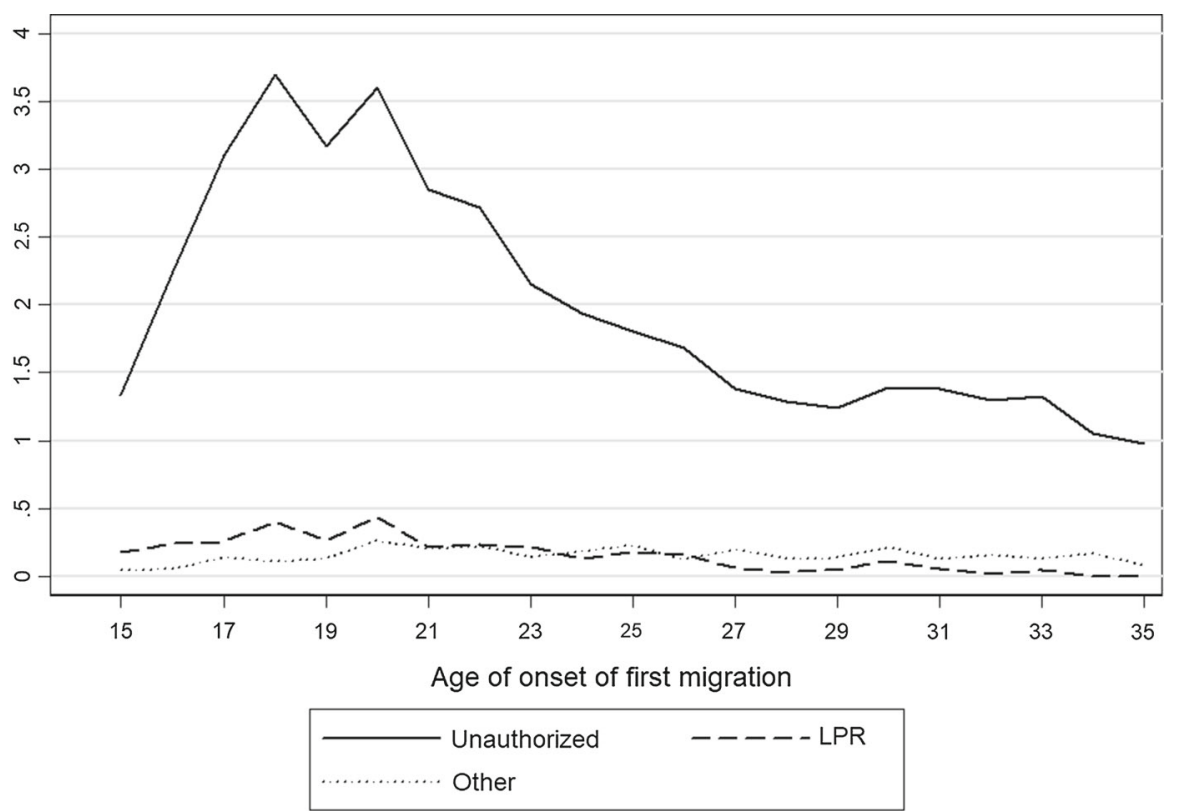

(a)

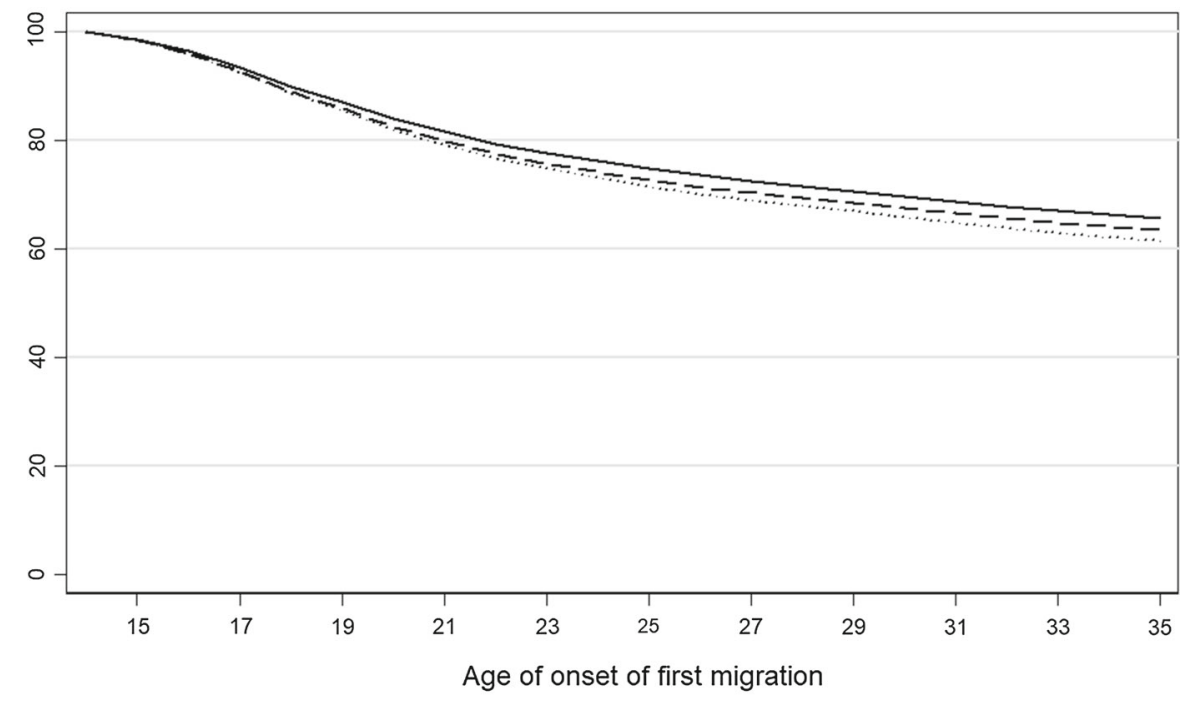

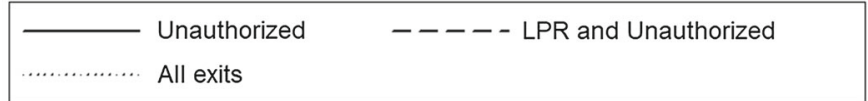

(b)

Fig. 4 Empirical migration and survival rates for age of onset of first migration. a Migration rates (\%). b Survival rates $(\%)$ 
the US. ${ }^{9}$ The share is measured in the year the spell started and is time-invariant. Dummies for states of birth are included to allow for state-fixed effects not captured by the municipality variables. ${ }^{10}$ Time-varying variables are included to control for the home community's socioeconomic characteristics. These are the community population, share of male labor force in manufacturing, and percentage of municipality labor force earning more than double the minimum wage. To control for time-varying labor demand factors, we include one-period lagged unemployment rate of the Hispanic and Latino population in the US. Lastly, to control for other US immigration policies that might have affected migration behavior we include 1 period lagged annual number of Mexican's deported from the US. We include deportation as a proxy variable for two other immigration laws followed the IRCA within the observation period. The immigration laws enacted in 1990 and 1996 made deportation procedure of unauthorized migrants easier. ${ }^{11}$ As Fig. 2 shows, deportations of Mexicans remained relatively stable until 1990 after which it increased substantially. As can be also seen, the IRCA has changed only the line-watch hours at the border, although the latter had also seen a strong increase since about 1994.

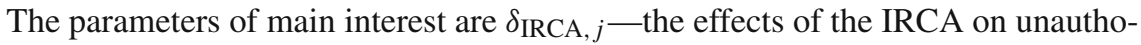
rized or legal migration to the US. The specification of the effect of the IRCA assumes that individual hazard rate shifts at the age that is equivalent to the year that the IRCA is effective and not before. For instance, if an individual in Mexico was 19 years of age at the time IRCA was enacted, we allow for a permanent shift in the individual's hazard rate of migration at the age 19. As the IRCA was enacted on Nov 6, 1986 we take the year 1987 as the year the IRCA went into effect. The timing of enactment of the law was difficult to be foreseen by migrants. Although the reform was discussed by policy-makers for about a decade, the debates around and opposition to the law by legislative authorities created an uncertainty about its implementation. ${ }^{12}$ After controlling for time trend, personal characteristics, home and destination characteristics, and other immigration policies, we expect that our measure of the average effect of the IRCA is not confounded by other factors that influence migration dynamics. Therefore, we assume that the IRCA caused a shift in the migration rates that is constant over time.

Duration dependence is specified as a step-function with $\lambda_{j}(t)=\exp \left(\Sigma_{k} \xi_{j, k} I_{k}(t)\right)$, where $k(=1, \ldots, 10)$ is a subscript for age categories and $I_{k}(t)$ are time-varying dummy variables that are one in subsequent categories, 9 of which are for individual ages (age $15, \ldots, 23)$ and the last interval is for ages above 24 years. Because we also estimate constant terms, we normalize $\xi_{j, 1}=0$.

\footnotetext{
9 Only $14 \%$ of our total sample are heads of households, $37 \%$ of whom have taken at least one trip to the US within our observation window. The rest of the sample consist of other members of the household.

10 For $92.4 \%$ of the individuals in the main sample, their state of birth and last state of household residence coincide.

11 The law of 1990 also made changes to the legal admissions quota.

12 Orrenius and Zavodny (2003) reached a similar conclusion that illegal immigrants did not change their behavior in expectation of the IRCA.
} 
The conditional density functions for the completed durations until migration to the US either as an unauthorized or as a legal migrant is

$$
\begin{aligned}
f^{u l}\left(t \mid x_{t}, D_{t}, v_{u}, v_{l}\right)= & \left(\left(\theta^{u}\left(t \mid x_{t}, D_{t}, v_{u}\right)+\theta^{l}\left(t \mid x_{t}, D_{t}, v_{l}\right)\right)\right. \\
& \times \exp \left(-\int_{0}^{t}\left(\left(\theta^{u}\left(s \mid x_{t}, D_{t}, v_{u}\right)+\theta^{l}\left(s \mid x_{t}, D_{t}, v_{l}\right)\right) d s\right.\right.
\end{aligned}
$$

We integrate out the unobserved heterogeneity component assuming that they follow a discrete distribution with four points of support and the associated probabilities

$$
\begin{array}{ll}
\operatorname{Pr}\left(v_{u}=v_{u, 1}, v_{l}=v_{l, 1}\right)=p_{1}, & \operatorname{Pr}\left(v_{u}=v_{u, 1}, v_{l}=v_{l, 2}\right)=p_{2} \\
\operatorname{Pr}\left(v_{u}=v_{u, 2}, v_{l}=v_{l, 1}\right)=p_{3}, & \operatorname{Pr}\left(v_{u}=v_{u, 2}, v_{l}=v_{l, 2}\right)=p_{4}
\end{array}
$$

which are modeled using a multinomial logit specification, $p_{h}=\frac{\exp \left(\rho_{h}\right)}{\Sigma_{h} \exp \left(\rho_{h}\right)}$, with $h=1,2,3,4$ and $\rho_{4}$ normalized to zero. Because we estimate constants, we also normalize $v_{u, 2}=v_{l, 2}=0$. In the specification of the likelihood function incomplete durations and the interval nature of our data are taken into account (see Altangerel and van Ours (2017) for details).

\subsection{Parameter Estimates Migration Rates}

The parameters of our model are estimated using the method of maximum likelihood and reported in Table 1. The first column shows the parameter estimates for the unauthorized migration rate and the second column shows parameter estimates for the legal migration rates. Initially, as indicated before, unobserved characteristics were assumed to follow a discrete distribution with four points of support. However, we found unobserved heterogeneity to be perfectly correlated across the two migration rates, i.e. we identified a discrete distribution with two points of support. Apparently, conditional on the observed characteristics, there are two types of migrants, those who are more likely to migrate with or without documentation and those who are less likely to migrate. The proportion of the latter in the sample is estimated to be $30 \%$.

The IRCA seems to have had a negative and significant effect on undocumented migration. It decreased the conditional probability of undertaking an undocumented trip to the US by $13 \%$. The effect of the IRCA on legal migration is positive but it does not differ significantly from zero. Furthermore, we find that education has a non-linear effect on the age of onset of migration. The hazard rate of migration is lower at the low end and at the high end of the educational distribution. Poorer economic opportunities in the home country trigger migration at an earlier age, especially undocumented, as can be seen from the effect of origin community characteristics. The effect of coming from a larger community, and a larger share of workers earning high wages in the community are negative and significant on the undocumented migration rate. The effect of home community size is similar on legal migration rates as well, but a greater share of workers earning high wages affects the legal migration rate positively. As 
Table 1 Parameter estimates of competing risk model for migration rates into the US: undocumented and legal

\begin{tabular}{|c|c|c|c|c|}
\hline & \multicolumn{2}{|l|}{ Undocumented } & \multicolumn{2}{|c|}{ LPR } \\
\hline \multicolumn{5}{|l|}{ Panel A. Baseline model } \\
\hline Effect of IRCA & $-0.140^{*}$ & $(0.076)$ & 0.104 & $(0.208)$ \\
\hline \multicolumn{5}{|l|}{ Personal characteristics } \\
\hline Years of education & $0.232 * * *$ & $(0.026)$ & $0.533 * * *$ & $(0.097)$ \\
\hline Years of education squared & $-0.017 * * *$ & $(0.001)$ & $-0.025^{* * *}$ & $(0.005)$ \\
\hline \multicolumn{5}{|l|}{ Community characteristics at origin } \\
\hline Size & $-0.083 * * *$ & $(0.031)$ & $-0.111 * *$ & $(0.049)$ \\
\hline Males in manufacturing & -0.005 & $(0.007)$ & $-0.027 * * *$ & $(0.008)$ \\
\hline Double min. wage & $-0.014 * * *$ & $(0.005)$ & $0.015^{* *}$ & $(0.007)$ \\
\hline Migrant community & $0.067 * * *$ & $(0.017)$ & $0.066 * * *$ & $(0.009)$ \\
\hline \multicolumn{5}{|c|}{ Immigration policy and unemployment at destination } \\
\hline Hispanic/Latino unemployment & $-0.063 * * *$ & $(0.014)$ & -0.036 & $(0.057)$ \\
\hline Deportation & $0.569 * * *$ & $(0.127)$ & 0.215 & $(1.001)$ \\
\hline Cohort & -0.076 & $(0.088)$ & 0.241 & $(0.276)$ \\
\hline Cohort squared & 0.003 & $(0.003)$ & -0.007 & $(0.008)$ \\
\hline Year trend & $0.397 * * *$ & $(0.107)$ & 0.441 & $(0.932)$ \\
\hline Year trend squared & $-0.005 * * *$ & $(0.001)$ & -0.007 & 0.013 \\
\hline Constant & $-15.141^{* * *}$ & (3.134) & -21.442 & $(26.129)$ \\
\hline \multicolumn{5}{|l|}{ Age dependence } \\
\hline 16 & $0.649 * * *$ & $(0.097)$ & $0.440^{*}$ & $(0.240)$ \\
\hline 17 & $1.114 * * *$ & $(0.117)$ & $0.662 * *$ & $(0.287)$ \\
\hline 18 & $1.433 * * *$ & $(0.129)$ & $1.301 * * *$ & $(0.370)$ \\
\hline 19 & $1.404 * * *$ & $(0.148)$ & $1.055 * * *$ & $(0.412)$ \\
\hline 20 & $1.643 * * *$ & $(0.166)$ & $1.701 * * *$ & $(0.426)$ \\
\hline 21 & $1.500 * * *$ & $(0.158)$ & $1.143 * *$ & $(0.513)$ \\
\hline 22 & $1.516^{* * *}$ & $(0.186)$ & $1.338 * *$ & $(0.540)$ \\
\hline 23 & $1.343 * * *$ & $(0.194)$ & $1.398 * *$ & $(0.594)$ \\
\hline $24+$ & $1.227 * * *$ & $(0.221)$ & $1.285^{*}$ & $(0.713)$ \\
\hline \multicolumn{5}{|l|}{ Unobserved heterogeneity } \\
\hline$\rho_{1}$ & \multicolumn{4}{|c|}{$-0.854 *(0.483)$} \\
\hline$v_{1}$ & $-2.145^{* * *}$ & $(0.800)$ & -1.142 & $(0.848)$ \\
\hline \multicolumn{5}{|l|}{ - Log-likelihood $=20428.1$} \\
\hline \multicolumn{5}{|l|}{ Panel B. Effects of IRCA components } \\
\hline Effect of IRCA & -0.133 & $(0.093)$ & & \\
\hline LPR admissions & $-0.128 * * *$ & $(0.046)$ & & \\
\hline Line-watch hours & 0.176 & $(0.292)$ & & \\
\hline
\end{tabular}


Table 1 continued

\begin{tabular}{lll}
\hline & Undocumented & LPR \\
\hline $\begin{array}{l}\text { Employer sanctions } \\
- \text { Log-likelihood }=20413.8\end{array}$ & 0.056 & $(0.138)$ \\
\hline
\end{tabular}

The table shows estimation results for a competing risk model for two types of entries into the US: undocumented and as an LPR permit holder. Size: (log) community population. All origin community and destination characteristics except for migrant community are time-varying variables. Origin state coefficients are not reported. Panel B: shows coefficients of the (log) annual LPR admission, (log) annual line-watch hours, and an indicator for active employee sanctions along with the baseline estimation. Models were estimated with the same specification as in Panel A; the IRCA dummy for age of onset of unauthorized migration and return from an unauthorized migration was supplemented with the (log) annual LPR admissions, (log) annual line-watch hours, and an indicator for years after 1988 for the beginning of employer sanctions. Based on 14,580 observations; in parentheses clustered standard errors at the level of the community; ${ }^{*} p<0.10,{ }^{* *} p<0.5,{ }^{* * *} p<0.01$

expected, having members of the community in the US increases both migration rates. This may be because a network in the US lowers migration costs and because it is easier to obtain an LPR permit as family member of a current migrant. Higher unemployment rates among Hispanics/Latino's in the US have a negative effect on migration rates although the effect on legal migration is not significantly different from zero. The laws enacted in 1990 and 1996 to expedite unauthorized migration deportation seem to have had a positive effect on the undocumented migration rates. There is a positive but nonlinear trend in the rate of undocumented migration. Duration dependence in the hazard rate has an inverted U-shape for unauthorized and legal migration as was shown in Fig. 4.

\subsection{Sensitivity Analysis and Simulation Results}

To check whether the effects of the IRCA can be related to one or more of its components, we added to the IRCA dummy variable in the main model time-varying variables signifying each major component of the law: the (log of) annual line-watch hours at the border for the enforcement, an indicator for active employer sanctions policy, and the (log of) the annual number of Mexican LPR recipients for the legalization component. The results presented in panel $\mathrm{B}$ indicate that the number of Mexican LPR recipients is significantly different from zero while line-watch hours and employers sanctions are not. This could be due to several factors. Reyes (2007) finds that border enforcement was positively associated with undocumented migration suggesting that for the enforcement to be effective a certain high level is necessary. Massey and Espinosa (1997) posit that preemptive migration might explain ineffective border policy if individuals undertake migration sooner to preempt further increases in border enforcement. Gathmann (2008) finds that migrants change their route of entry when border enforcement does not increase evenly in all places.

Massey and Espinosa (1997) found that having legalized family members greatly increased the odds of an undocumented trip to the US. Thus, unauthorized migration rates may have been affected by the undocumented entry of family members of legalized migrants. To allow for this possibility, we exclude from the sample the 22 
Table 2 Predicted undocumented migration proabilities by age 30

\begin{tabular}{lllr}
\hline & Before & After \\
& IRCA & IRCA & $\Delta$ \\
\hline Median individual & 44.1 & 40.2 & -3.9 \\
Double min. wage $=16.5$ (25-th percentile) & 49.6 & 45.6 & -4.0 \\
Double min. wage $=39.7$ (75-th percentile) & 37.6 & 34.0 & -3.6 \\
Migrant community $=1.5$ (25-th percentile) & 37.6 & 34.0 & -3.6 \\
Migrant community $=11.2$ (75-th percentile) & 56.1 & 52.1 & -4.0 \\
Hispanic/Latino unemployment $=7.4$ (25-th percentile) & 46.8 & 42.8 & -4.0 \\
Hispanic/Latino unemployment $=10.5$ (75-th percentile) & 41.3 & 37.5 & -3.8 \\
\hline
\end{tabular}

The table shows predicted migration rates by or at age 30 before and after IRCA for a selection of individuals in Mexico. All numbers are in percentages. The median characteristics are taken to be as follows (median of the sample): He is born in 1967, has 9 years of education as of the survey, and comes of age 14 in a community where $5 \%$ of household heads are in the US. He comes from a community of a population of 5000, where $26 \%$ of male labor force work in manufacturing, and $27 \%$ of workers earn above double the minimum wage. During the observation period, the median US unemployment rate for men of Hispanic/Latino origin was $8.85 \%$ and about 20,000 unauthorized Mexican migrants were deported in a year. He comes from the state Jalisco. Before (after) IRCA estimations assume that the entire spell unaffected (affected) by IRCA

households with at least one legalized member. As was to be expected, the parameter estimates are not affected by this exclusion.

To illustrate the magnitude of some determinants and the effects of the IRCA on unauthorized migrants we perform simulations of undocumented migration rates by age 30 based on the characteristics of the median migrant and the parameter estimates of Table 1. As shown in Table 2, the unauthorized migration probability by age 30 for a Mexican man with the median characteristics was about $44 \%$ before and $40 \%$ after the IRCA, a drop of 4\%-points.

The simulations also show important wage effects. Before the IRCA, if the share of the population earning more than double the minimum wage increases from the 25 -th to the 75 -th percentile, the undocumented migration probability by age 30 goes down with about $12 \%$-point. There is also a big effect of migrant networks. An increase of migration network ratio from the 25 -th to the 75 -th percentile leads to about $18.5 \%$ point increase in undocumented migration by age 30 . Similarly, the effect of US labor market conditions is considerable. If the Hispanic/Latino unemployment rate increases from its 25-th to the 75-th percentile, undocumented migration rates fall by about 5.5 percentage points. The IRCA-effect is about the same for all types of situations. This is due to the IRCA-effect being specified as a multiplicative effect in the migration rate.

\section{Return Migration Rates}

\subsection{Descriptives}

We analyze the duration of the first migration trip to the US which started in the years 1976-1985. The spells are observed for up to 12 years until an individual returns to 
Mexico or is right censored by the end of observation period or the survey year. We include only first trips due to availability of data.

The empirical rates of return from the trip indicate that the trip features strong negative duration dependence. The top graph of Fig. 5 shows the empirical (hazard) rates of return from the first trip. Legal migrants have a significantly lower return rate in the first decade after migration compared to that of unauthorized migrants. The bottom graph of Fig. 5 shows indeed that the duration of the first legal migration trip to the US is substantially longer than the duration of other types of migration. The median duration of unauthorized and other migration is about 1-2 years while the median duration of the first trip of legal migration is about 12 years.

\subsection{Statistical Model}

The duration of the first trip of a migrant to the US is measured in years. We specify the return rate at duration $\tau$ conditional on observed characteristics $x_{2, t}$ and unobserved characteristics $w$ as

$$
\begin{aligned}
& \theta^{j}\left(\tau \mid x_{2, t}, D_{\tau}, L_{\tau}, w_{j}\right) \\
& \quad=\gamma_{j}(\tau) \exp \left(x_{2, t} \alpha_{j}+\sigma_{\text {IRCA }, j} D_{\tau}+\sigma_{\text {Legal }, u} L_{\tau}+w_{j}\right) \quad \text { for } j=u, l
\end{aligned}
$$

in which $j$ indicates the nature of the first trip in terms of the legal framework: unauthorized or legal. Furthermore, vector $x_{2, t}$ contains in addition to the characteristics in $x_{t}$ characteristics of the first trip in terms of first main destination (California, Illinois, Texas or other state), type of first main occupation in the US (agricultural, unskilled manufacturing, skilled manufacturing, service or other industry), and the initial wage in the US. The time-varying background variables representing the home community and destination in $x_{t, 2}$ are lagged by 1 year. For the time-invariant network variable we take the value observed at the start of the migration trip. The variable $D_{\tau}$ indicates whether a spell interval covers a post-IRCA period, i.e. occurring in or after 1987. By introducing the variable $L_{\tau}$ that indicates whether an unauthorized immigrant obtains a LPR permit during an interval, we allow for a shift in the hazard rate when an illegal immigrant becomes legal during the first trip. ${ }^{13}$ This is done to separate the effect of the IRCA on unauthorized immigrants from the effect of legalization. Confounding of newly legalized migrants with other unauthorized migrants will cause a bias in measuring the effect of the IRCA as the maintenance of a legal status has a requirement of continued stay in the US which reduces the hazard rate of return. The main parameters of interest are the $\sigma_{\text {IRCA, } j}$ that indicate the effect of the IRCA on return migration. For both return hazards we allow for unobserved heterogeneity which is specified as a discrete distribution with two points of support. ${ }^{14}$

\footnotetext{
13 Legalized migrants include migrants legalized under the IRCA or the Immigration and Nationality Act. Note that we assume this legalization to be exogenous to the return migration rate.

14 Based on LR test statistics we choose the model without unobserved heterogeneity for the return hazard from an LPR migration and normalize $w_{l, 1}=w_{l, 2}=0$. In a separate analysis we investigated whether there is correlation between unobservables in the migration rate and the return migration rate. This turned out not to be the case.
} 

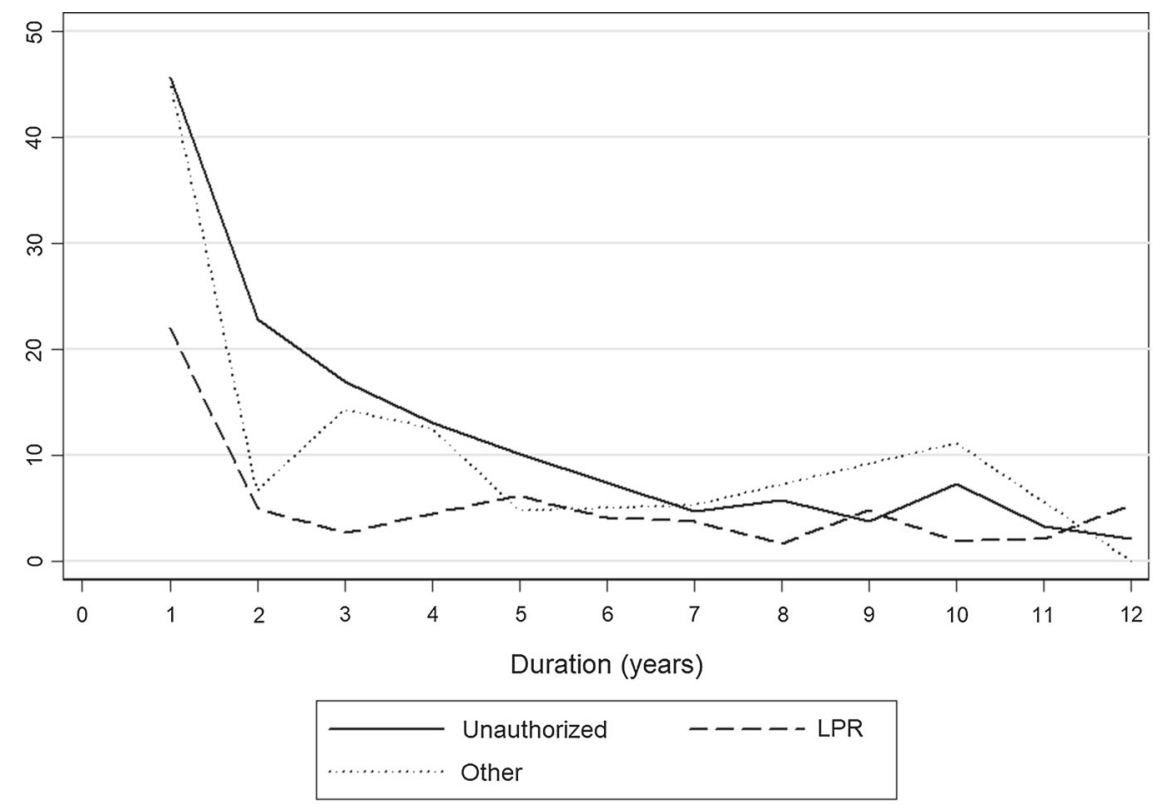

(a)

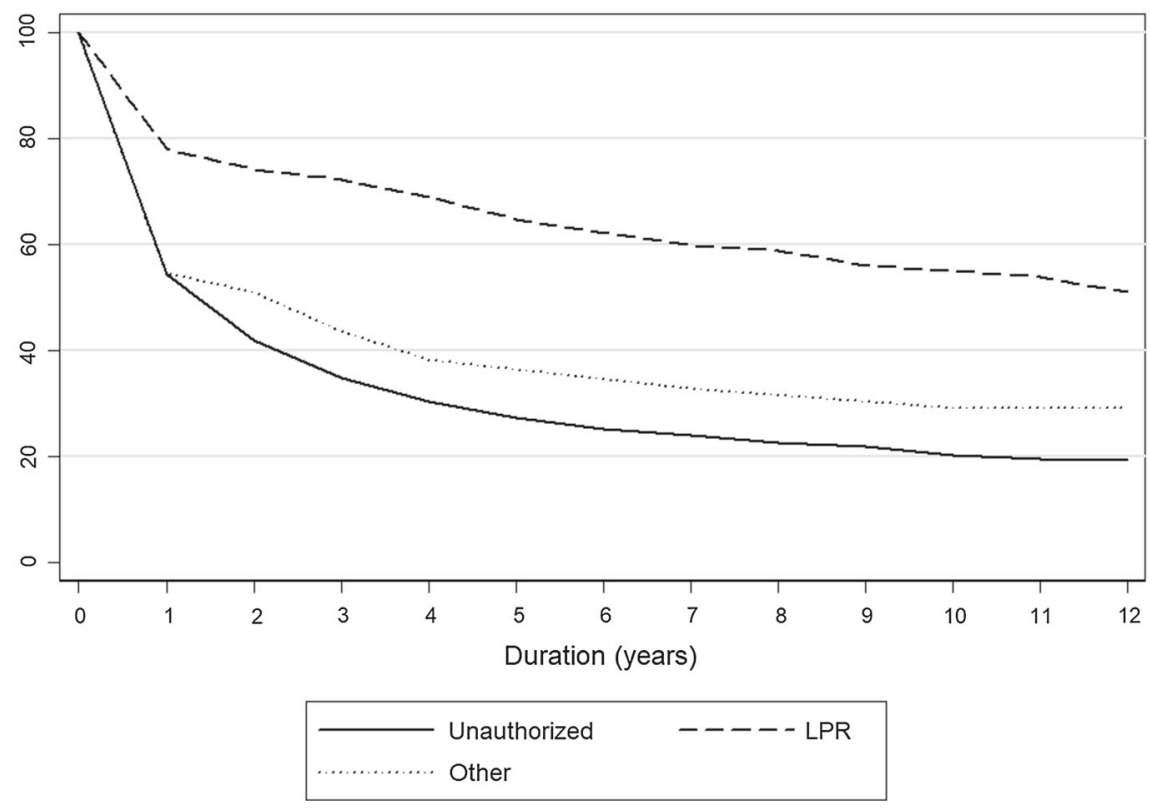

(b)

Fig. 5 Empirical hazard and survival rates of return migration. a Return rates (\%). b Survival rates (\%) 
The conditional density functions for the completed durations of the first trip either as an unauthorized or as a legal migrant is specified for $j=u, l$ as follows:

$$
\begin{aligned}
& g^{j}\left(\tau \mid x_{2, t}, D_{\tau}, L_{\tau}, w_{j}\right)=\theta^{j}\left(\tau \mid x_{2, t}, D_{\tau}, L_{\tau}, w_{j}\right) \\
& \quad \exp \left(-\int_{0}^{\tau} \theta^{j}\left(s \mid x_{2, t}, D_{\tau}, L_{\tau}, w_{j}\right)\right) d s
\end{aligned}
$$

We integrate out the unobserved heterogeneity component with points of support $w_{j, 1}$ and $w_{j, 2}$ and associated probabilities $p_{j}$ and $1-p_{j}$ where $p_{j}=\exp \left(\varrho_{j}\right) /(1+$ $\left.\exp \left(\varrho_{j}\right)\right)$. We normalize $w_{j, 2}=0$ and since duration is measured in years, we account for the interval nature of the data in the log-likelihood contribution as before.

\subsection{Parameter Estimates Return Migration Rates}

The parameter estimates of the effect of the IRCA on the return migration rate of the first trip to the US and the effect of legalization of unauthorized migrants are shown in Table 3. These estimates indicate that legalization of an undocumented migrant decreased the return rate by about $34 \%$. After accounting for this effect, the IRCA is estimated to increase the return migration rate for undocumented migrants, by about $34 \%$. The IRCA did not have a significant effect on the return rates of legal migrants.

As predicted, the results show that there is a negative duration dependence in the return rate from first migration while there is a stark difference in the return rates for legal migrants between the first year and later years. By the second year of migration, the conditional probabilities of return for both unauthorized and legal migrants drop by more than $80 \%$. As in the case of duration until first migration, the results indicate presence of unobserved heterogeneity in the return rate of undocumented migrants. We identify two types of individuals in the sample, one with a shorter duration and one with a much longer duration. The proportion of the latter in the sample is estimated to be about $6 \%$ of undocumented migrants.

Education has a negative but nonlinear effect on the return rate for undocumented immigrants and a positive effect on the return rate for legal migrants. Age at entry has a positive nonlinear effect on the hazard rate of legal migrants. Age at entry has no effect on the return rate of unauthorized migrants. Unauthorized migrants to Texas tend to have the highest return rates. The parameter estimate for the migrant community variable indicates that presence of members of the home community in the US stimulates higher rates of return migration. This might result from several factors. Presence of a network reduces initial costs of migration leading to less time in the US to recuperate the cost. Also, as suggested by Lindstrom (1996), due to less cost per trip the presence of a network might encourage circular migration.

We have noted that agricultural workers are overrepresented in the MMP sample compared to the Mexican migrant population in the US. Workers in agriculture represent $20 \%$ of the migrant sample. We check the robustness of our findings in respect to return migration by analyzing a sub-sample which excludes workers in agriculture, but not in other agricultural sectors such as animal husbandry, forestry and fisheries. Now, all parameter estimates are insignificantly different from zero (panel B of Table 
Table 3 Parameter estimates of return rates from the first trip to the US by migrant status

\begin{tabular}{|c|c|c|c|c|}
\hline & \multicolumn{2}{|c|}{ Undocumented } & \multicolumn{2}{|c|}{ LPR } \\
\hline \multicolumn{5}{|l|}{ Panel A. Baseline model } \\
\hline Effect of IRCA & $0.292 * *$ & $(0.135)$ & 0.344 & $(0.396)$ \\
\hline Effect of legalization & $-0.422 *$ & $(0.221)$ & & \\
\hline \multicolumn{5}{|l|}{ Personal characteristics } \\
\hline Years of education & -0.039 & $(0.026)$ & $0.121 * * *$ & $(0.039)$ \\
\hline Years of education squared & $0.003 *$ & $(0.002)$ & & \\
\hline Age at entry & 0.089 & $(0.062)$ & $0.327 *$ & $(0.185)$ \\
\hline Age squared & -0.001 & $(0.001)$ & $-0.007 *$ & $(0.004)$ \\
\hline Married & $0.277 * *$ & $(0.116)$ & 0.482 & $(0.717)$ \\
\hline \multicolumn{5}{|l|}{ Community characteristics at origin } \\
\hline Size & 0.039 & $(0.030)$ & -0.025 & $(0.089)$ \\
\hline Double min. wage & 0.002 & $(0.006)$ & $-0.025 * *$ & $(0.011)$ \\
\hline Males in manufacturing & -0.005 & $(0.006)$ & $0.058 * * *$ & $(0.018)$ \\
\hline Migrant community & $0.013 * *$ & $(0.006)$ & $0.028 * *$ & $(0.011)$ \\
\hline \multicolumn{5}{|l|}{ Destination characteristics } \\
\hline Hispanic/Latino unemployment in state & 0.006 & $(0.015)$ & $-0.095 *$ & $(0.055)$ \\
\hline Deportation & -0.083 & $(0.122)$ & 0.461 & $(0.481)$ \\
\hline Initial wage & $-0.033 * * *$ & $(0.008)$ & $-0.042 * *$ & $(0.016)$ \\
\hline California & -0.002 & $(0.115)$ & -0.146 & $(0.230)$ \\
\hline Illinois & -0.004 & $(0.147)$ & -0.268 & $(0.770$ \\
\hline Texas & $0.526^{* * *}$ & $(0.164)$ & -0.029 & $(0.460)$ \\
\hline \multicolumn{5}{|l|}{ Occupation in the US } \\
\hline Agricultural & $0.647 * * *$ & $(0.095)$ & $1.749 * * *$ & $(0.289)$ \\
\hline Unskilled manufact. & 0.043 & $(0.095)$ & 0.212 & $(0.311)$ \\
\hline Skilled manufact. & $-0.208^{* *}$ & $(0.094)$ & 0.144 & $(0.403)$ \\
\hline Service & $0.228 * *$ & $(0.107)$ & -0.490 & $(0.490)$ \\
\hline Cohort & 0.052 & $(0.230)$ & -0.209 & (1.188) \\
\hline Cohort squared & -0.001 & $(0.004)$ & 0.003 & $(0.020)$ \\
\hline Constant & -1.328 & $(4.329)$ & -7.321 & (20.909) \\
\hline \multicolumn{5}{|l|}{ Duration dependence } \\
\hline Year 2 & $-0.719 * * *$ & $(0.078)$ & $-1.176^{* * *}$ & $(0.333)$ \\
\hline Year 3 & $-0.981 * * *$ & $(0.113)$ & $-1.817 * * *$ & $(0.544)$ \\
\hline Year 4 & $-1.192 * * *$ & $(0.141)$ & $-1.305^{* * *}$ & $(0.400)$ \\
\hline Year 5 & $-1.425^{* * *}$ & $(0.183)$ & $-0.955^{* *}$ & 0.483 \\
\hline Year 6 & $-1.700 * * *$ & $(0.196)$ & $-1.303 * *$ & $(0.646)$ \\
\hline Year 7 & $-2.160 * * *$ & $(0.247)$ & $-1.397 * *$ & $(0.549)$ \\
\hline Year 8 & $-1.922 * * *$ & $(0.229)$ & $-2.189 * * *$ & $(0.847)$ \\
\hline Year 9 & $-2.342 * * *$ & $(0.283)$ & -1.082 & $(0.808)$ \\
\hline Year $10+$ & $-1.738 * * *$ & $(0.244)$ & -0.921 & $(0.743)$ \\
\hline
\end{tabular}


Table 3 continued

\begin{tabular}{|c|c|c|c|c|}
\hline & \multicolumn{2}{|c|}{ Undocumented } & \multicolumn{2}{|c|}{ LPR } \\
\hline \multicolumn{5}{|c|}{ Unobserved heterogeneity } \\
\hline$\varrho$ & $-2.762 * * *$ & $(0.598)$ & & \\
\hline$w_{1}$ & $-2.085^{* *}$ & $(0.685)$ & & \\
\hline - Log-likelihood & 5000.7 & & 364.1 & \\
\hline Observations & 3258 & & 310 & \\
\hline \multicolumn{5}{|c|}{ Panel B. Sensitivity analysis: No agricultural workers } \\
\hline Effect of IRCA & 0.210 & $(0.154)$ & 0.471 & $(0.432)$ \\
\hline Effect of legalization & -0.337 & $(0.237)$ & & \\
\hline - Log-likelihood & 3688.9 & & 295.5 & \\
\hline Observations & 2195 & & 247 & \\
\hline
\end{tabular}

The table shows estimation results for the hazard rates of return from either an undocumented or a legal migration with an LPR permit. Size: (log) community population. All origin community and destination characteristics except for migrant community and initial destination and wage are time-varying variables. Origin state coefficients are not reported. Panel B: The sensitivity analysis excludes sample of migrants who worked in agriculture. In parentheses clustered standard errors at the level of the community; ${ }^{*} p<$ $0.10,{ }^{* *} p<0.5,{ }^{* * *} p<0.01$

3). From this we conclude that our results are indeed sensitive to the inclusion of agricultural workers.

\section{Concluding Remarks}

In our study, we measure the effects of an immigration reform, the IRCA, on the male migration rate from Mexico to the US and the return migration rate from the US to Mexico. We use the rich survey dataset provided by the Mexican migration project. Our study contributes to the current literature on the effect of the IRCA by measuring the overall effect of the policy and using a change in individual's behavior over time to identify the effect. In doing so, we attempt to control explicitly for the effect of selection and other confounding factors.

We provide evidence that the IRCA may have been effective in reducing the unauthorized immigrant inflow once we take into account confounding factors. After we control for the trend in the migration rate, individual characteristics, and variable push and pull factors, the IRCA appears to have reduced unauthorized migration to the US. We also find that the IRCA did not have significant effects on the rate of legal migration or the duration of the first legal migration trip.

The IRCA as a comprehensive reform has had a substantial effect on immigration. It consisted of different policy measures that intended to control and deter unauthorized migration by increasing the difficulty of illegal entry, and of finding and keeping a job while unauthorized. The IRCA seems to have affected unauthorized migration to the US largely through its legalization program. Since this legalization program was active only for some years, the long term effects of the IRCA are probably limited. In the two decades following the IRCA, the number of unauthorized immigrants increased 
threefold and the duration of stay increased as well. The literature on the effect of IRCA has reached the conclusion that, if IRCA has been effective, it was only in the short period immediately after the IRCA, but was not effective in reducing unauthorized immigration in the long term (Orrenius and Zavodny 2003). This is in line with our main findings.

Open Access This article is distributed under the terms of the Creative Commons Attribution 4.0 International License (http://creativecommons.org/licenses/by/4.0/), which permits unrestricted use, distribution, and reproduction in any medium, provided you give appropriate credit to the original author(s) and the source, provide a link to the Creative Commons license, and indicate if changes were made.

\section{Appendix A: Information About our Data}

As shown in panel A of Table 4, the median Mexican individual in the sample has 9 years of education, while median unauthorized migrants have less education. ${ }^{15}$ In the year that an individual turned 14, there were on average 8 household heads in the US for every 100 households in the community. ${ }^{16}$ Furthermore, $73 \%$ of males participate in the labor force, and $21 \%$ earned more than double the minimum wage. Compared to the median individual in the sample, those from smaller communities with lower level of economic opportunities have higher migration rates, especially of unauthorized migration. Migration rates, especially those of legal migration, are higher in Mexican communities with a larger network in the US. In the sample of 14,580 individuals in Mexico in our observation period 29\% eventually immigrate as an unauthorized migrant and $3 \%$ as legal migrant to the US.

Panel B of Table 4 provides descriptive statistics about return migration rates. The number of migrants used for the analysis of return migration is smaller than the number of Mexican individuals who immigrated to the US (see Panel A) as we restrict the immigrants in the analysis of return rates to those entering the US between 1976 and 1985 . It shows that $79 \%$ of unauthorized migrants and $48 \%$ of legal migrants have returned to Mexico from their first trip. The median ages at migration are 21 and 20 for unauthorized and legal migrants respectively. Compared to the legal migrants, unauthorized return migrants are from smaller communities with smaller shares of community members in the US. The destination for more than half of the migrant sample is California. Taken together, about three quarters of all migrants are headed to the state of California, Illinois, or Texas. More than one-fifth of both unauthorized and legal migrants work in agriculture. ${ }^{17}$ The average initial hourly wage of legal migrants is $60.2 \%$ higher than that of unauthorized migrants.

\footnotetext{
15 Education is measured in years of education and characterizes the migrant at the time of the survey.

16 The 'migrant community' variable is created using the life history data available for household-head migrants comparing it with the surveyed community.

17 The occupation variable measures the category of the first main occupation held during the trip.
} 
Table 4 Descriptive statistics

\begin{tabular}{llll}
\hline a. Duration until the first trip & Undocumented & LPR & All \\
\hline Sample size & 4239 & 365 & 14,580 \\
Spell starting year, median & 1981 & 1980 & 1981 \\
Years of education, median (mean) & $6(7.3)$ & $9(8.9)$ & $9(8.4)$ \\
Infrastructure and Socioeconomic Indicators in Municipality (at age 14): & & 8000 \\
Community population, median & 4000 & 6000 & 37,000 \\
Municipality population, median & 24,000 & 38,000 & 73 \\
Males in LF, mean & 72 & 72 & 21 \\
Males in manufacturing, mean & 21 & 22 & 21 \\
Double min. wage, mean & 17 & 20 & 8 \\
Migrant community, mean & 11 & 14 & 10.8 \\
Socioeconomic and Policy Indicators in the US (at age 14$):$ & 10.9 & 10.7 & 13,746 \\
Unemployment of Hispanic or Latino men & 13,757 & 14,108 & \\
Deportation of Mexicans, mean & & &
\end{tabular}

\begin{tabular}{lll}
\hline b. Duration of the first trip & Undocumented & LPR \\
\hline Sample size & 3258 & 310 \\
of which not censored (returned) & $2579(79 \%)$ & $148(48 \%)$ \\
1 US trip if migrant \% & 43 & 73 \\
Up to 2 US trips if migrant \% & 64 & 79 \\
Up to 3 US trips if migrant \% & 75 & 84 \\
Spell starting year, median & 1981 & 1982 \\
Unauthorized migrants legalized, \% & 12.5 & \\
Number legalized & 664 & 20 \\
Age at migration, mean & 21 & 30
\end{tabular}

Infrastructure and Socioeconomic Indicators in Municipality at the beginning of first trip

Community population, median

$\begin{array}{ll}4000 & 6000 \\ 24,000 & 38,000 \\ 71 & 70 \\ 21 & 22 \\ 16 & 18 \\ 15 & 17\end{array}$

Municipality population, median

Males in LF, mean

Males in manufacturing, mean

Double min. wage, mean

Migrant community, mean

15

$14.9(17)$

Initial wage, median (mean)

$9.3(10.8)$

Unemployment of Hispanic or Latino men, by state

Deportation of Mexicans, mean

13,384

Destination: Illinois \%

Destination: Texas \% 
Table 4 continued

\begin{tabular}{lll}
\hline b. Duration of the first trip & Undocumented & LPR \\
\hline Occupation: Agriculture e.o. \% & 35 & 23 \\
Occupation: Unskilled manufacturing $\%$ & 22 & 25 \\
Occupation: Skilled manufacturing \% & 11 & 20 \\
Occupation: Service \% & 16 & 11 \\
\hline
\end{tabular}

Duration until first trip: age of onset minus 14, Years of education as measured at the time of survey, Males in LF: percentage males in municipal labor force, Males in manufacturing: percentage of male labor force in manufacturing, Double min. wage: percentage of workers in municipality who earn more than twice the minimum wage, Migrant community: share of household-heads who were in the US in the year the spell started, US unemployment: national unemployment rate of Hispanic or Latino men aged 16 and above in the US in the year an individual's spell has started, US unemployment by state: state's unemployment rate of Hispanic or Latino men aged 16 and above in the first destination state of migrants in the year an individual's spell has started (source: US Bureau of Labor Statistics), Deportation of Mexicans: Number of deportations of Mexicans from the US in the year an individual's spell has started, Wage: self-reported first US wage (2010 US dollars), Married at migration: marital status at the start of the first US trip (information available for communities 72-154), Agriculture e.o: agriculture, husbandry, forestry, and fishery

\section{References}

Altangerel, K., \& van Ours, J. C. (2017). Immigration reform and the dynamics of Mexican migration. CEPR Discussion Paper 12032.

Amuedo-Dorantes, C., \& Bansak, C. (2011). The impact of amnesty on labor market outcomes: A panel study using the legalized population survey. Industrial Relations, 50(3), 443-471.

Amuedo-Dorantes, C., Bansak, C., \& Raphael, S. (2007). Gender differences in the labor market: Impact of IRCA's amnesty provisions. American Economic Review, 97(2), 412-416.

Baker, B. C. (2010). Naturalization rates among IRCA immigrants: A 2009 update. Technical report. DHS Office of Immigration Statistics.

Baker, B., \& Rytina, N. (2013). Estimates of the unauthorized immigrant population residing in the United States: January 2012. Technical report. DHS Office of Immigration Statistics.

Baker, S. R. (2015). Effects of immigrant legalization on crime. American Economic Review, 105(5), 210213.

Boeri, T., \& van Ours, J. C. (2013). The economics of imperfect labor markets (2nd ed.). Princeton: Princeton University Press.

Brownell, P. (2017). Employer sanctions and the wages of mexican immigrants. RSF, 3(4), 70-96.

Clark, X., Hatton, T. J., \& Williamson, J. G. (2007). Explaining U.S. immigration, 1971-1998. Review of Economics and Statistics, 89(2), 359-373.

Cooper, B., \& O'Neil, K. (2005). Lessons from the Immigration Reform and Control Act of 1986. Technical report 3, Task force on immigration and America's future. Migration Policy Institute.

Daniels, R. (2002). Coming to America: A history of immigration and ethnicity in American life (2nd ed.). New York: Harper Perennial.

Donato, K. M., Durand, J., \& Massey, D. S. (1992). Stemming the tide? Assessing the deterrent effects of the Immigration Reform and Control Act. Demography, 29(2), 139-157.

Durand, J., \& Massey, D. S. (2004a). Appendix: The Mexican migration project. In J. Durand \& D. S. Massey (Eds.), Crossing the border: Research from the Mexican migration project (Vol. 16, pp. 321-336). New York: Russell Sage Foundation.

Durand, J., \& Massey, D. S. (2004b). What we learned from the Mexican migration project. In J. Durand \& D. S. Massey (Eds.), Crossing the border: Research from the Mexican migration project (Vol. 1, pp. 1-16). New York: Russell Sage Foundation.

Gathmann, C. (2008). Effects of enforcement on illegal markets: Evidence from migrant smuggling along the southwestern border. Journal of Public Economics, 92, 1926-1941. 
Hanson, G. H. (2006). Illegal migration from Mexico to the United States. Journal of Economic Literature, 44, 869-924.

Kossoudji, S. A., \& Cobb-Clark, D. A. (2000). IRCA's impact on the occupational concentration and mobility of newly-legalized Mexican men. Journal of Population Economics, 13, 81-98.

Li, S. (2016). The determinants of mexican mmigrant' duration in the united states: Family composition, psychic ccost, and human capital. IZA Journal of Migration, 5(2), 1-28.

Lindstrom, D. P. (1996). Economic opportunity in Mexico and return migration from the United States. Demography, 33(3), 357-374.

Massey, D. S., \& Espinosa, K. E. (1997). What's driving Mexico-US migration? A theoretical, empirical, and policy analysis. American Journal of Sociology, 102(4), 939-999.

Mexican Migration Project and Latin American Migration Project. (2012). MMP/LAMP interviewer's manual.

Orrenius, P. M., \& Zavodny, M. (2003). Do amnesty programs reduce ondocumented immigration? Evidence from IRCA. Demography, 40(3), 437-450.

Passel, J. S., \& Cohn, D. (2016). Overall number of U.S. Unauthorized immigrants holds steady since 2009. Technical report. Washington, D.C.: Pew Research Center.

Quinn, M. A. (2014). Crossing the border and migration duration. Contemporary Economic Policy, 32(4), $1-19$.

Reyes, B. (2001). Immigrant trip duration: The case of immigrants from western Mexico. International Migration Review, 35(4), 1185-1204.

Reyes, B. I. (2004). Changes in trip duration for Mexican immigrants to the United States. Population Research and Policy Review, 23, 235-257.

Reyes, B. (2007). The impact of US immigration policy on Mexican unauthorized immigration. The University of Chicago Legal Forum, 22, 131-154.

Rytina, N. (2002). IRCA legalization effects: Lawful permanent residence and naturalization through 2001. INS Office of Policy and Planning.

US Congress. Senate. (1996). Proposals for immigration reform: Hearing before the subcommittee on immigration and refugee affairs of the committee on the judiciary on the impact of immigration on the U.S. and proposals to reform U.S. immigration laws, August 3, 1994.

U.S. General Accounting Office. (1990). Immigration reform: Employer sanctions and the question of discrimination. Technical report. General Accounting Office.

U.S. General Accounting Office. (1992). Southwest border enforcement affected by mission expansion. Technical report. United States General Accounting Office.

White, M. J., Bean, F. D., \& Espenshade, T. J. (1990). The U.S. 1986 Immigration Reform and Control Act and undocumented migration to the United States. Population Research and Policy Review, 9, 93-116. 